\title{
Chapter 5 \\ Translational Medicine of Stem Cells: Central \\ Nervous System Regeneration and Modeling \\ Neurological Diseases
}

\author{
Hideyuki Okano
}

\begin{abstract}
We have been conducting research on regeneration of the damaged central nervous system, which includes (i) regrowth of the disrupted neuronal axons, (ii) replenishment of lost neural cells, and (iii) recovery of lost neural functions. In particular, we have investigated cell therapy for treating spinal cord injury. Considering the ethical issues related to fetal cells and embryonic stem cells, there is increasing interest in stem cell technology involving induced pluripotent stem (iPS) cells. Here, we wish to introduce our achievements in iPS cell-based therapy. In addition to their application for cell therapy, iPS cell technologies provide versatile tools for investigation of the pathophysiology of various diseases. Indeed, disease model mice do not always recapitulate the pathophysiology of human diseases. However, iPS cell technology can provide some solutions because neural cells at various developmental stages and a wide variety of cells with the same genetic information as that of patients can be obtained for further investigation. Through these investigations, I have had numerous collaborations with life science industries, including pharmaceutical companies, and generated various patents. Some examples of these achievements will be discussed here.
\end{abstract}

\section{The Challenge of Regeneration of the Central Nervous System}

It had been long believed that the damaged central nervous system (CNS) does not regenerate upon injury [1]. However, we have been challenging this dogma for many years by taking advantage of various biotechnologies, including stem cells [2-11], in collaboration with academia and various pharmaceutical companies.

\footnotetext{
H. Okano $(\bowtie)$

Department of Physiology, School of Medicine, Keio University,

35 Shinanomachi, Shinjuku-ku, Tokyo 160-8581, Japan

e-mail: hidokano@a2.keio.jp
} 
Before introducing the details of our past and on-going research, I wish to introduce the concepts of regeneration of the CNS, which include (i) regrowth of disrupted neuronal axons, (ii) replenishment of lost neural cells, and (iii) recovery of lost neural functions. Investigation of CNS regeneration is indeed an exciting and profound research field, but also provides enormous opportunities for industry-university cooperation. In fact, through investigations of CNS regeneration and stem cell biology, I have obtained 30 patents and filed 57 patents pending.

(i) Regrowth of disrupted neuronal axons

Axonal regeneration hardly takes place in the damaged CNS because of the presence of large amounts of inhibitors $[9,10]$, including myelin-derived proteins (e.g. MAG, Nogo-A, and OMgp) [12-17], and glial scar-derived factors (e.g. CSPG) [18, 19], and extracellular matrix-derived factors (e.g. semaphorins). In a previous collaboration with Dainippon Sumitomo Pharma Co. Ltd., we demonstrated the therapeutic effects of a specific inhibitory compound (SM-216289) against semaphorin3A (Sema3A) [20], a major inhibitor of axonal regeneration [21-23], in spinal cord injury (SCI) using a rat complete transection model. Remarkably, we found that this Sema3A inhibitor induced significant functional recovery as well as enhanced axonal regeneration at the lesion site and robust Schwann cell-mediated myelination. This evidence suggests the possibility of using Sema3A inhibitors for the treatment of human SCI patients in the future, which is being continuously investigated through the collaboration between our group at Keio University and Dainippon Sumitomo Pharma Co. Ltd. In addition to treatment of SCI, we found another application of the Sema3A inhibitor in the ophthalmological field. In collaboration with the Department of Ophthalmology at Keio University School of Medicine and Dainippon Sumitomo Pharma Co. Ltd., we showed that the Sema3A inhibitor was able to treat peripheral nerve damage of the cornea. Treatment with the Sema3A inhibitor promoted a robust network of regenerating nerves as well as functional recovery of corneal sensation through subconjunctival injections in a mouse keratoplasty model [24], suggesting a novel therapeutic strategy for treating peripheral nerve damage of the cornea.

(ii) Replenfishment of lost neural cells

It is obvious that replenishment of lost neural cells will be a very important aim of stem cell technology. In our previous studies [25-30], we found that transplanted neural stem cells (NSCs) survived and differentiated into neurons, astrocytes, and oligodendrocytes, which are three major cellular components of the CNS. Graft-derived neurons formed synapses with host neurons and integrated with host neuronal circuits. Graft-derived oligodendrocytes were shown to participate in re-myelination of host axons in SCI models [28, 30], which significantly contributes to functional recovery after SCI [30]. It is possible that graft-derived astrocytes and undifferentiated NSCs produce various trophic factors that support angiogenesis [27-29], cellular survival, and axonal regeneration of host axons including 5-HT-positive raphe-spinal tracts involved 
in the locomotive functions of hindlimbs [27-29]. Thus, these findings suggest that both cellular replacement mechanisms and trophic mechanisms are responsible for the effects of stem cell therapy in SCI models. The details of stem cell therapy for treating SCI will be described in the later sections.

(iii) Recovery of lost neural functions

Considering the therapeutic applications of stem cells, it is obvious that recovery of lost neural functions is an important aspect of regeneration of the damaged CNS. For functional recovery, we are interested in rehabilitation and its combination with blockade of the inhibitors of axonal regeneration [31], and/or stem cell transplantation.

\section{NSCs and Stem Cell Therapy for Treating SCI}

NSCs are somatic stem cells in the CNS, which are characterized by their multipotency and self-renewal. A single NSC is capable of generating various kinds of cells within the CNS, including neurons, astrocytes, and oligodendrocytes. Because of these characteristics, there has been a strong research focus on NSCs and neural progenitor cells for both basic developmental biology and therapeutic applications for treating the damaged CNS [2].

\subsection{Basic Biology and Tools for Investigation of NSCs}

It is understood that (i) specific immunocytochemical markers, (ii) selective culture methods, and (iii) technologies for the prospective identification and isolation of NSCs and early precursor cells (neural stem/precursor cells, NS/PCs) have greatly contributed to the rapid progress of the investigation of NSCs [8].

(i) Specific immunocytochemical markers Specific marker molecules for NSCs include Musashi1 (an RNA-binding protein) [32-38], nestin [39, 40], and some Sox family transcription factors [41].

(ii) Selective culture methods

The neurosphere method involves suspension culture with fibroblast growth factor-2 (FGF-2) and/or epidermal growth factor in a defined medium [42], which has been widely used as a versatile method for selective expansion of NSCs. Neurosphere culture allowed us to expand NSCs in an undifferentiated state. NS/PCs obtained by neurosphere culture have been used for transplantation into patients with SCI and Parkinson's disease. We applied neurosphere culture for efficient induction of NSCs from pluripotent stem cells including embryonic stem (ES) cells and induced pluripotent stem (iPS) cells [43-45]. Briefly, we generated embryoid bodies (EBs) from mouse ES/ iPS cells in the presence of neural inducers (noggin or retinoic acid), resulting 
in neurally biased differentiation of ES cells and a substantial number of NSCs. The NSCs within EBs were then expanded in the presence of FGF-2 to give rise to primary neurospheres that were subsequently passaged to form secondary neurospheres. Interestingly, when we induced the differentiation of primary neurospheres, they exclusively gave rise to neurons, but not glial cells. The majority of neurons derived from primary neurospheres were early projection neurons including forebrain type cholinergic neurons, mesencephalic dopaminergic neurons and spinal motor neurons. However, when we induced the differentiation of secondary neurospheres, they gave rise to neurons, astrocytes, and oligodendrocytes. Neurons derived from secondary neurons, including GABAergic interneurons as the major population, were different from those derived from primary neurospheres. Furthermore, tertiary neurospheres gave rise to a higher proportion of glial cells. Therefore, this in vitro differentiation system of mouse pluripotent stem cells probably recapitulates the change of differentiation potential of NSCs, which occurs in vivo [46]. Using these methods for neural differentiation of pluripotent stem cells, we generated patents, including "Process for Producing Nerve Stem Cells, Motor Neurons, and GABAergic Neurons from Embryonic Stem Cells," and "Remedy for Dysmnesia," and licensed out these patents and related technologies to various pharmaceutical companies and bio-ventures.

(iii) Technologies for the prospective identification and isolation of NSCs and early precursor cells

For the prospective identification of NSCs, combinations of antibodies against cell surface antigens $[47,48]$ and NSC-specific fluorescence reporters [4956] have been used [8]. For the latter strategy, we constructed a reporter gene consisting of cDNA encoding a fluorescent protein (green fluorescent protein, Venus, Kusabira Orange, or ffLuc-cp156 [57]), which was placed under the control of the 2nd intronic enhancer of the nestin gene or enhancer elements of the Musashil gene for specific expression in NSCs. By taking advantage of these strategies using cell type-specific promoter/enhancer elements and fluorescent reporter genes, we generated several patents for the prospective identification and isolation of NSCs ("Enriched Preparation of Human Fetal Multipotential Neural Stem Cells") and dopaminergic neurons ("Method of Concentrating and Separating DOPAMINergic Neurons") [58].

In addition to (i)-(iii), there are rapidly accumulating studies of the signaling mechanisms involved in the self-renewal and differentiation of NSCs. In the related field, we have published numerous scientific reports and generated various patents including "Numb Protein Expression Inhibitor Making Use Musashi," "Method of Detecting Activation of Notch Signal Transmission System," "Signal Transduction System Activator," "Agent for Inhibiting Proliferation of Neural Stem Cells," and "Method of Promoting Subsistence and/or Proliferation of Neural Stem Cells and Promoting Extension of Neurite, Promoter therefore, Pharmaceutical Composition Containing Neural Stem Cells, Method of Assay and Method of Screening." 


\subsection{Stem Cell Therapy for Treating SCI}

\subsubsection{Pathophysiology of SCI}

The pathophysiology of SCI is known to change over time after the initial injury. SCI is initiated by primary mechanical trauma (the so called "primary injury") and followed by a series of secondary events (the so called "secondary injury") [8]. The secondary injury includes hemorrhage, ischemia, and hypoxia (which take place within seconds), production of pro-inflammatory cytokines and glutamate cytotoxicity (which take place within minutes), and production of free radicals and nitric oxide, protease activation, and neutrophil invasion (which take place within hours). These events characterize the strong inflammation at the acute phase of SCI. The acute phase of SCI lasts for several days after the primary mechanical trauma, which is followed by delayed events (the so called "subacute phase") including neural apoptosis, astrogliosis, and axonal demyelination. The subacute phase is followed by an irreversible stage (the so called "chronic phase") including severe axonal degeneration, cyst formation, and permanent loss of spinal functions. The chronic phase is considered to begin at 6 weeks in rodents and 6 months in humans after the primary mechanical trauma. This phenomenon is not observed in salamanders in which the spinal cord regrows even after tail amputation [59]. The damaged spinal cord hardly regenerates in adult mammalian animals because of limited activation of endogenous stem cells and axonal regeneration, which is why there is a need for blockade of the inhibitors of axonal regeneration, and transplantation of NSCs for treating the SCIs of humans.

\subsubsection{Interventions at the Acute Phase}

In the acute phase of SCI, inflammatory cells such as neutrophils, hematogenous macrophages (blood-borne macrophages), and resident microglia accumulate at the lesion site. Because pro-inflammatory cytokines such as tumor necrosis factor $\alpha$, interleukin (IL)-1 $\beta$, and IL-6 are major regulators of inflammation, these cytokines are likely targets for potential pharmaceutical interventions for treating SCI [60]. Among them, IL-6 induces the activation and invasion of microglia/macrophages within SCIs. Thus, in collaboration with Chugai Pharmaceutical Co. Ltd, we administered an anti-mouse IL-6 receptor antibody, MR16-1, to a mouse SCI model, resulting in improved functional recovery with reduced inflammation and astrogliosis, and enhanced tissue sparing [61]. Furthermore, we have investigated the mechanism of action of the anti-MR16-1 in more detail by focusing on the effect of temporary inhibition of IL-6 signaling in macrophages and microglia after SCI [60]. We found that MR16-1 treatment reduced the infiltration of macrophages, but increased the number of microglia at the SCI. Thus, temporary inhibition of IL-6 signaling must have induced switching of the major inflammatory cell type at the lesion from hematogenous macrophages to resident microglia, resulting in improved 
tissue sparing and debris clearance for promotion of neural repair after SCI. Notably, a humanized antibody against the human IL-6 receptor (Actemra; tocilizumab) is already used clinically, and our findings suggest its potential application for the treatment of SCI patients at the acute phase. Keio University and Chugai Pharmaceutical Co. Ltd have filed patents covering the therapeutic actions of blocking antibodies against IL-6 signaling during the acute phase of SCI ("Therapeutic Agent for Spinal Cord Injury Comprising Interleukin-6") in various countries.

\subsubsection{Stem Cell Transplantation at the Sub-acute Phase}

Considering the time course of secondary injury, the most appropriate time point for transplantation of NSCs is important. In rodent SCI models, we performed transplantation of NS/PCs at 9 days after injury, i.e., after the acute inflammatory phase and before the astroglial scar becomes prominent [8]. In mice, we found that transplantation of NS/PCs at the chronic phase did not result in functional recovery [62]. Thus, the chronic phase of SCI is not appropriate for therapeutic transplantation. The formation of large cysts and the development of glial scarring during the chronic phase might inhibit axonal regeneration (Nishimura et al. Submitted). In the case of humans and considering the time course of inflammation, it is assumed that NS/PCs should be transplanted by 4 weeks after the primary mechanical trauma. In relation to stem cell therapy of SCIs, we generated a patent entitled "Central Nervous System Neural Progenitor Cell which Induces Synapse-Forming Neurons in the Spinal Cord."

\subsubsection{Non-human Primate Models of SCI}

While most studies of SCI have used rodent models, it is not easy to directly correlate the results obtained in rodent models to clinical cases because of the functional and anatomic differences of the spinal cord between rodents and primates. Previously, we developed a non-human primate model of contusive SCI at the C5 level in the common marmoset. This model consisted of mild, moderate and severe contusive SCIs that were induced by dropping one of three different weights $(15$, 17 , or $20 \mathrm{~g}$ ) onto the $\mathrm{C} 5$ level from a height of $50 \mathrm{~mm}$. We also developed behavioral assays to monitor the motor functions of these common marmoset models of SCI by measurements of spontaneous motor activity, as well as bar grip and cage climbing tests [63]. Using this model, we verified the therapeutic effects of transplantation of human fetal NSCs [64] and infusion of hepatocyte growth factor (HGF) [65]. By confirming the safety and utility in this non-human primate model, we initiated a Phase 1 clinical trial of HGF infusion for treatment of patients with amyotrophic lateral sclerosis in collaboration with Professor Masashi Aoki at Tohoku University and Kringle Pharma Co Ltd. [66]. We also filed a patent for the common marmoset model of SCI in both Japan and the USA ("Method of Constructing Spinal Injury Model Monkey and Utilization Thereof"). 


\subsubsection{Sources of Stem Cells for Treating SCI}

We have demonstrated that transplantation of human fetal NSCs into a common marmoset model of SCI results in significant functional recovery. However, because of the ethical controversies, we are not allowed to perform clinical trials using fetal cells. Human ES cells are also somewhat controversial. Therefore, we became interested in iPS cell-derived NS/PCs, directly induced NSCs [67], and neural crest stem cells [68] for transplantation into patients. These cells can be derived from adult tissues, including a patient's own tissue, and are therefore not ethically controversial.

\section{3 iPS Cell-Based Therapy for Treating SCI}

\subsubsection{Brief Summary of iPS Cell Technology}

iPS cell technology was developed by Professor Shinya Yamanaka, the 2012 Nobel laureate for Physiology or Medicine, and colleagues at Kyoto University. In 2006, they published a study showing that somatic cells, such as adult skin fibroblasts, can be reprogrammed into ES cell-like pluripotent stem cells by retroviral transduction of four genes encoding transcription factors, i.e., Oct4, Sox2, Klf4, and c-Myc [69]. Since 2006, we have had a close collaboration with the Yamanaka Laboratory, aiming for iPS cell-based therapy for treating SCI patients. In 2007, establishment of human iPS cells using retroviral or lentiviral transduction of reprogramming factors was reported by Yamanaka [70] and Thomson [71]. Subsequently, various methods have been published (reviewed by Okano [72] for generating integration-free iPS cells, including episomal vectors, the Sendai viral vector, and modified RNA).

\subsubsection{Transplantation of NSCs Derived from iPS Cells}

First, we examined transplantation of NSCs derived from mouse iPS cells into a mouse SCI model. However, the investigation was not as straightforward as we had expected. We had already established mouse ES cells [43, 44], and induced various mouse iPS cell lines into secondary neurospheres. The resultant mouse iPS cell-derived secondary neurospheres gave rise to neurons, astrocytes, and oligodendrocytes, which was irrespective of their somatic origin or method of iPS cell production [45], in a similar manner as that of mouse ES cell-derived secondary neurospheres. However, when we transplanted these mouse iPS cell-derived secondary neurospheres into mouse brains, varying tumorigenic propensities were observed depending on the somatic origin of the iPS cells [45]. These observations indicated that epigenetic memory and completeness of reprogramming were involved in the tumorigenic propensities of iPS cell-derived NSCs. Subsequently, we transplanted 
non-tumorigenic iPS cell-derived NSCs (primary or secondary neurospheres) into mouse thoracic contusion injury models (Th10) to examine their therapeutic effects.

Interestingly, we found that transplantation of secondary neurospheres, but not primary neurospheres, resulted in significant and long-lasting functional recovery, indicating the importance of glial cells. We found that transplanted iPS cell-derived secondary neurospheres gave rise to neurons, astrocytes, and oligodendrocytes, and re-myelination was induced by graft-derived oligodendrocytes. Conversely, transplantation of tumorigenic iPS cell-derived secondary neurospheres into SCI model mice resulted in functional recovery, but the effects were transient. Eventually, transplanted animals suffered from strong paralysis due to the effects of tumors. Thus, the safety issue concerning tumorigenicity is crucial for iPS cell-based therapy of SCI.

Human iPS cells can be induced to differentiate into NSCs in a similar manner as that of mouse iPS cells, although additional passage(s) are required to obtain both neurons and glia from iPS cell-derived neurospheres. Thus, in the case of humans, we used tertiary neurosphere instead of secondary neurospheres for the following transplantation experiments. We screened human iPS cell lines and found that NSCs derived from the 201B7 human iPS cell line were non-tumorigenic (Okada et al., submitted). We transplanted 201B7 human iPS cell-derived NSCs into mouse [29] and common marmoset SCI models (Kobayashi et al., submitted), and found that grafted cells gave rise neurons, astrocytes, and oligodendrocytes and induced functional recovery without any signs of tumorigenesis.

\subsubsection{Future Direction of Cell Therapy for Treating SCI Using Reprogramming Technologies}

Thus far, we have transplanted NSCs derived from mouse and human iPS cells into mouse and non-human primate SCI models, which results in functional recovery. Furthermore, using appropriate cell lines, there were no signs of tumorigenesis in transplanted animals during the time course of the observation. For clinical application in the future, there are some concerns that need to be addressed. Considering that the critical time window for transplantation is within 4 weeks after SCI (primary mechanical trauma) and establishment of human iPS cells and subsequent induction of NSCs, which produce both neurons and glia, requires $\sim 180$ days, it is essential to prepare clinical grade banks (or stocks) of iPS cells and iPS cell-derived NSCs in advance. Clinical grade cell banks would allow these cells to be transplanted into any patient within the critical period. In addition, before iPS cellbased therapy can be used in the clinic, we believe that the safety issues should be addressed as follows: (1) usage of integration-free iPS cells, (2) selection of an appropriate neural differentiation method, (3) selection of appropriate iPS cell clones by somatic origin, reprogramming, epigenetic characterization, and flow 
cytometric analysis, (4) pre-evaluation of tumorigenesis in vivo, and (5) elimination of graft-derived tumors [72].

\section{Disease Models}

There is increasing interest in iPS cell-based modeling of diseases [73]. In fact, disease model mice do not always recapitulate the pathophysiology of human diseases. Furthermore, it is extremely difficult to investigate what is taking place in vivo during the onset of disease, particularly neurological and psychiatric diseases, partly because there is poor accessibility to pathological foci in the brain. These aspects complicate the investigation of human neurology. However, iPS cell technology can provide some solutions because neural cells at various developmental stages and a wide variety of cells with the same genetic information as that of patients can be obtained for further investigation. In my laboratories, we have been characterizing various neurological and psychiatric diseases that are classified into the following categories: (1) diseases caused by disrupted gene regulation, (2) diseases caused by structural abnormalities of the nervous system, (3) diseases caused by abnormal neural functions, (4) diseases caused by abnormal metabolism in the nervous system, and (5) late-onset neurological diseases including Alzheimer's disease [74] and Parkinson's disease [75]. Characterization of iPS cells derived from pediatric neurological disorders may recapitulate disease processes, at least partially, which may contribute to drug development and future therapies.

Acknowledgments This work was supported by grants from the Project for Realization of Regenerative Medicine; and Support for Core Institutes for iPS Cell Research from the Ministry of Education, Culture, Sports, Science, and Technology of Japan (MEXT). The original works described here were performed by my group in collaboration with Dr. Masaya Nakamura and his colleagues at the Department of Orthopedic Surgery, Keio University School of Medicine.

Open Access This article is distributed under the terms of the Creative Commons Attribution Noncommercial License which permits any noncommercial use, distribution, and reproduction in any medium, provided the original author(s) and source are credited.

\section{References}

1. Ramón y Cajal S (1928) Degeneration and regeneration of the nervous system. Oxford University Press, Oxford

2. Okano H (2002) The stem cell biology of the central nervous system. J Neurosci Res 69:698-707

3. Okano H (2002) Neural stem cells: progression of basic research and perspective for clinical application. Keio J Med 51:115-128

4. Okano H (2003) Making and repairing the mammalian brain: introduction. Semin Cell Dev Biol 14:159 
5. Okano H, Okada S, Nakamura M, Toyama Y (2005) Neural stem cells and regeneration of injured spinal cord. Kidney Int 68:1927-1931

6. Okano H, Nakamura M, Toyama Y (2006) Stem cell therapies for injured spinal cord. Inflamm Regen 26:18-28

7. Okano H, Sawamoto K (2008) Neural stem cells: involvement in adult neurogenesis and CNS repair. Philos Trans R Soc Lond B Biol Sci 363:2111-21122

8. Okano H (2010) Neural stem cells and strategies for the regeneration of the central nervous system. Proc Jpn Acad Ser B 86:438-450

9. Okano H (2011) Strategic approaches to regeneration of a damaged central nervous system. Cornea 30(Suppl 1):S15-S18

10. Okano H, Kaneko S, Okada S, Iwanami A, Nakamura M, Toyama Y (2007) Regeneration-based therapies for spinal cord injuries. Neurochem Int 85:2332-2342

11. Okano H, Sakaguchi M, Ohki K, Suzuki N, Sawamoto K (2007) Regeneration of the central nervous system using endogenous repair mechanisms. J Neurochem 102:1459-1465

12. Schwab ME, Kapfhammer JP, Bandtlow CE (1993) Inhibitors of neurite growth. Annu Rev Neurosci 16:565-595

13. GrandPre T, Nakamura F, Vartanian T, Strittmatter SM (2000) Identification of the Nogo inhibitor of axon regeneration as a reticulon protein. Nature 403:439-444

14. Chen MS et al (2000) Nogo-A is a myelin-associated neurite outgrowth inhibitor and an antigen for monoclonal antibody IN-1. Nature 403:434-439

15. Domeniconi M et al (2002) Myelin-associated glycoprotein interacts with the Nogo66 receptor to inhibit neurite outgrowth. Neuron 35:283-290

16. Olson L (2002) Medicine: clearing a path for nerve growth. Nature 416:589-590

17. Wang $\mathrm{KC}$ et al (2002) Oligodendrocyte-myelin glycoprotein is a Nogo receptor ligand that inhibits neurite outgrowth. Nature 417:941-944

18. Morgenstern DA, Asher RA, Fawcett JW (2002) Chondroitin sulphate proteoglycans in the CNS injury response. Prog Brain Res 137:313-332

19. Silver J, Miller JH (2004) Regeneration beyond the glial scar. Nat Rev Neurosci 5:146-156

20. Kaneko S, Iwanami A, Nakamura M, Kishino A, Kikuchi K, Shibata S, Okano HJ, Ikegami T, Moriya A, Konishi O, Nakayama C, Kumagai K, Kimura T, Sato Y, Goshima Y, Taniguchi M, Ito M, He Z, Toyama Y, Okano H (2006) A selective Sema3A-inhibitor enhances regenerative responses and functional recovery of the injured spinal cord. Nat Med 12:1380-1389

21. Pasterkamp RJ et al (1999) Expression of the gene encoding the chemorepellent semaphorin III is induced in the fibroblast component of neural scar tissue formed following injuries of adult but not neonatal CNS. Mol Cell Neurosci 13:143-166

22. Pasterkamp RJ, Anderson PN, Verhaagen J (2001) Peripheral nerve injury fails to induce growth of lesioned ascending column axons into spinal cord scar tissue expressing the axon repellent Semaphorin3A. Eur J Neurosci 13:457-471

23. De Winter F et al (2002) Injury-induced class 3 semaphorin expression in the rat spinal cord. Exp Neurol 175:61-75

24. Omoto M, Yoshida S, Miyashita H, Kawakita T, Yoshida K, Kishino A, Kimura T, Shibata S, Tsubota K, Okano H, Shimmura S (2012) The Semaphorin 3A inhibitor SM-345431 accelerates peripheral nerve regeneration and sensitivity in a murine corneal transplantation model. PLoS One 7:e47716

25. Ogawa Y, Sawamoto K, Miyata T, Miyao S, Watanabe M, Nakamura M, Bregman BS, Koike M, Uchiyama Y, Toyama Y, Okano H (2002) Transplantation of in vitro-expanded fetal neural progenitor cells results in neurogenesis and functional recovery after spinal cord contusion injury in adult rats. J Neurosci Res 69:925-933

26. Okano H, Ogawa Y, Nakamura M, Kaneko S, Iwanami A, Toyama A (2003) Transplantation of neural stem cells into the spinal cord after injury. Semin Cell Dev Biol 14:191-198

27. Kumagai G, Okada Y, Yamane J, Kitamura K, Nagoshi N, Mukaino M, Tsuji O, Fujiyoshi K, Okada S, Shibata S, Toh S, Toyama Y, Nakamura M, Okano H (2009) Roles of ES cell-derived gliogenic neural stem/progenitor cells in functional recovery after spinal cord injury. PLoS One 4:e7706 
28. Tsuji O, Miura K, Okada Y, Fujiyoshi K, Nagoshi N, Kitamura K, Kumagai G, Mukaino M, Nishino M, Tomisato S, Higashi H, Ikeda E, Nagai T, Kohda K, Takahashi K, Okita K, Katoh H, Matsuzaki Y, Yuzaki M, Toyama Y, Nakamura M, Yamanaka S, Okano H (2010) Therapeutic effect of the appropriatelly evaluated 'safe' iPS cells for spinal cord injury. Proc Natl Acad Sci USA 107:12704-12709

29. Nori S, Okada Y, Yasuda A, Tsuji O, Takahashi Y, Kobayashi Y, Fujiyoshi K, Koike M, Uchiyama Y, Ikeda E, Toyama Y, Yamanaka S, Masaya N, Okano H (2011) Grafted human induced pluripotent stem cell-derived neurospheres promotes motor functional recovery after spinal cord injury in mice. Proc Natl Acad Sci USA 108:16825-16830

30. Yasuda A, Tsuji O, Shibata S, Nori S, Takano M, Kobayashi Y, Takahashi Y, Fujiyoshi K, Hara CM, Miyawaki A, Okano HJ, Toyama Y, Nakamura M, Okano H (2011) Significance of remyelination by transplanted neural stem/progenitor cells into the injured spinal cord. Stem Cells 29:1983-1994

31. García-Alías G, Barkhuysen S, Buckle M, Fawcett JW (2009) Chondroitinase ABC treatment opens a window of opportunity for task-specific rehabilitation. Nat Neurosci 12:1145-1151

32. Sakakibara S, Imai T, Aruga J, Nakajima K, Yasutomi D, Nagata T et al (1996) MouseMusashi-1, a neural RNA-binding protein highly enriched in the mammalian CNS stem cell. Dev Biol 176:230-242

33. Sakakibara S, Okano H (1997) Expression of neural RNA-binding proteins in the post-natal CNS: implication of their roles in neural and glial cells development. J Neurosci 17:8300-8312

34. Kaneko Y, Sakakibara S, Imai T, Suzuki A, Nakamura Y, Sawamoto K et al (2000) Musashi1: an evolutionally conserved marker for CNS progenitor cells including neural stem cells. Dev Neurosci 22:138-152

35. Okano H, Imai T, Okabe M (2002) Musashi: a translational regulator of cell fates. J Cell Sci 115:1355-1359

36. Okano H, Kawahara H, Toriya M, Nakao K, Shibata S, Takao I (2005) Function of RNA binding protein Musashi-1 in stem cells. Exp Cell Res 306:349-356

37. Good P, Yoda A, Sakakibara S, Yamamoto A, Imai T, Sawa H et al (1998) The human Musashi homolog 1 (MSI1) gene encoding the homologue of Musashi/Nrp-1, a neural RNA-binding protein putatively expressed in CNS stem cells and neural progenitor cells. Genomics 52:382-384

38. Muto J, Imai T, Ogawa D, Nishimoto Y, Okada Y, Mabuchi Y, Kawase T, Iwanami A, Mischel PS, Saya H, Yoshida K, Matsuzaki Y, Okano H (2012) RNA-binding protein Musashi1 modulates glioma cell growth through the post-transcriptional regulation of Notch and PI(3) Kinase/ Akt signaling pathways. PLoS One 7:e33431

39. Hockfield S, McKay RD (1985) Identification of major cell classes in the developing mammalian nervous system. J Neurosci 5:3310-3328

40. Lendahl U, Zimmerman LB, McKay RD (1990) CNS stem cells express a new class of intermediate filament protein. Cell 60:585-595

41. Pevny LH, Sockanathan S, Placzek M, Lovell-Badge R (1998) A role for SOX1 in neural determination. Development 125:1967-1978

42. Reynolds BA, Weiss S (1992) Generation of neurons and astrocytes from isolated cells of the adult mammalian central nervous system. Science 255:1707-1710

43. Naka H, Nakamura S, Shimazaki T, Okano H (2008) Requirement for COUP-TFI and II in the temporal specification of neural stem cells in central nervous system development. Nat Neurosci 11:1014-1023

44. Okada Y, Matsumoto A, Shimazaki T, Enoki R, Koizumi A, Ishii S, Itoyama Y, Sobue G, Okano H (2008) Spatio-temporal recapitulation of central nervous system development by ES cell-derived neural stem/progenitor cells. Stem Cells 26:3086-3098

45. Miura K, Okada Y, Aoi T, Okada A, Takahashi K, Okita K, Nakagawa M, Koyanagi M, Tanabe K, Ohnuki M, Ogawa D, Ikeda E, Okano H, Yamanaka S (2009) Variation in the safety of inducedpluripotent stem cell lines. Nat Biotechnol 27:743-745 
46. Okano H, Temple S (2009) Cell types to order: temporal specification of CNS stem cells. Curr Opin Neurobiol 19:112-119

47. Rietze RL, Valcanis H, Brooker GF, Thomas T, Voss AK, Bartlett PF (2001) Purification of a pluripotent neural stem cell from the adult mouse brain. Nature 412:736-739

48. Uchida N, Buck DW, He D, Reitsma MJ, Masek M, Phan TV et al (2000) Direct isolation of human central nervous system stem cells. Proc Natl Acad Sci USA 97:14720-14725

49. Roy NS, Benraiss A, Wang S, Fraser RA, Goodman R, Couldwell WT, Nedergaard M, Kawaguchi A, Okano H, Goldman SA (2000) Promoter-targeted selection and isolation of neural progenitor cells from the adult human ventricular zone. J Neurosci Res 59:321-331

50. Roy NS, Wang S, Jiang L, Kang J, Benraiss A, Harrison-Restelli C, Fraser RA, Couldwell WT, Kawaguchi A, Okano H, Nedergaard M, Goldman SA (2000) In vitro neurogenesis by progenitor cells isolated from the adult human hippocampus. Nat Med 6:271-277

51. Kawaguchi A, Miyata T, Sawamoto K, Takashita N, Murayama A, Akamatsu W, Ogawa M, Okabe M, Tano Y, Goldman SA, Okano H (2001) Nestin-EGFP transgenic mice: visualization of the self-renewal and multipotency of CNS stem cells. Mol Cell Neurosci 17:259-273

52. Sawamoto K, Nakao N, Kakishita K, Ogawa Y, Toyama Y, Yamamoto A, Yamaguchi M, Mori K, Goldman SA, Itakura T, Okano H (2001) Generation of dopaminergic neurons in the adult brain from mesencephalic precursor cells labeled with a nestin-GFP transgene. J Neurosci 21:3895-3903

53. Keyoung HM, Roy NS, Benraiss A, Louissaint A Jr, Suzuki A, Hashimoto M, Rashbaum WK, Okano H, Goldman SA (2001) High-yield selection and extraction of two promoter-defined phenotypes of neural stem cells from the fetal human brain. Nat Biotechnol 19:843-850

54. Murayama A, Matsuzaki Y, Kawaguchi A, Shimazaki T, Okano H (2002) Flow cytometric analysis of neural stem cells in the developing and adult mouse brain. J Neurosci Res 69:837-847

55. Kanki H, Shimabukuro MK, Miyawaki A, Okano H (2010) "Color Timer" mice: visualization of neuronal differentiation with fluorescent proteins. Mol Brain 3:5

56. Kawase S, Imai T, Miyauchi-Hara C, Yaguchi K, Nishimoto Y, Fukami SI, Matsuzaki Y, Miyawaki A, Itohara S, Okano H (2011) Identification of a novel intronicenhancer responsible for the transcriptional regulation of Musashil in neural stem/progenitor cells. Mol Brain 4:14

57. Hara-Miyauchi C, Tsuji O, Hanyu A, Okada S, Yasuda A, Fukano T, Akazawa C, Nakamura M, Imamura T, Matsuzaki Y, Okano HJ, Miyawaki A, Okano H (2012) Bioluminescent system for dynamic imaging of cell and animal behavior. Biochem Biophys Res Commun 419(2):188-193

58. Sawamoto K, Nakao N, Kobayashi K, Matsushita N, Takahashi H, Kakishita K, Yamamoto A, Yoshizaki T, Terashima T, Murakami F, Itakura T, Okano H (2001) Visualization, direct isolation, and transplantation of midbrain dopaminergic neurons. Proc Natl Acad Sci USA 98:6423-6428

59. McHedlishvili L, Mazurov V, Grassme KS, Goehler K, Robl B, Tazaki A, Roensch K, Duemmler A, Tanaka EM (2012) Reconstitution of the central and peripheral nervous system during salamander tail regeneration. Proc Natl Acad Sci USA 109:E2258-E2266

60. Mukaino M, Masaya Nakamura M, Yamada O, Okada S, Satoru Morikawa S, Iwanami A, Ikegami T, Ohsugi Y, Tsuji O, Katoh H, Matsuzaki Y, Toyama Y, Liu M, Okano H (2010) Anti IL-6 receptor antibody administered to the injured spinal cord accelerates repair process by modifying inflammatory cell recruitment. Exp Neurol 224(2):403-414

61. Okada S, Nakamura M, Mikami Y, Shimazaki T, Mihara M, Ohsugi Y, Iwamoto Y, Yoshizaki K, Kishimoto T, Toyama Y, Okano H (2004) Blockade of interleukin-6 receptor suppresses reactive astrogliosis and ameliorates functional recovery in experimental spinal cord injury. J Neurosci Res 76:265-276

62. Okada S, Ishii K, Yamane J, Iwanami A, Ikegami T, Iwamoto Y, Nakamura M, Miyoshi H, Okano HJ, Contag CH, Toyama Y, Okano H (2005) In vivo imaging of engrafted neural stem cells: its application inevaluating the optimal timing of transplantation for spinal cord injury. FASEB J 19:1839-1841 
63. Iwanami A, Yamane J, Katoh H, Nakamura M, Momomoshima S, Ishii H, Tanioka Y, Tamaoki N, Nomura T, Toyama Y, Okano H (2005) Establishment of graded spinal cord injury model in a non-human primate: the common marmoset. J Neurosci Res 80:172-181

64. Iwanami A, Kakneko S, Nakamura M, Kanemura Y, Mori H, Kobayashi S, Yamasaki M, Momoshima S, Ishii H, Ando K, Tanioka Y, Tamaoki N, Nomura T, Toyama Y, Okano H (2005) Transplantation of human neural stem/progenitor cells promotes functional recovery after spinal cord injury in common marmoset. J Neurosci Res 80:182-190

65. Kitamura K, Fujiyoshi K, Yamane J, Toyota F, Hikishima K, Nomura T, Funakoshi H, Nakamura T, Aoki M, Toyama Y, Okano H, Nakamura M (2011) Human hepatocyte growth factor promotes functional recovery in primates after spinal cord injury. PLoS One 6:e27706

66. Okano H (2012) The first clinical trial in Tohoku University Hospital after the Great East Japan Earthquake: the heroic efforts of my friend, Professor Masashi Aoki. Keio J Med 61:3-9

67. Matsui T, Takano M, Yoshida K, Ono S, Fujisaki C, Matsuzaki Y, Yoshiaki Toyama Y, Nakamura M, Okano H, Akamatsu W (2012) Neural stem cells directly differentiated from partially reprogrammed fibroblasts rapidly acquire gliogenic competency. Stem Cells 30:1109-1119

68. Nagoshi N, Shibata S, Kubota Y, Nakamura M, Nagai Y, Satoh E, Okada Y, Mabchi Y, Katoh H, Okada S, Fukuda K, Suda T, Matsuzaki Y, Toyama Y, Okano H (2008) Ontogeny and multipotency of neural crest-derived stem cells in bone marrow, dorsal root ganglia and whisker pad of adult rodents. Cell Stem Cell 2:392-403

69. Takahashi K, Yamanaka S (2006) Induction of pluripotent stem cells from mouse embryonic and adult fibroblast cultures by defined factors. Cell 126:663-676

70. Takahashi K, Tanabe K, Ohnuki M, Narita M, Ichisaka T, Tomoda K, Yamanaka S (2007) Induction of pluripotent stem cells from adult human fibroblasts by defined factors. Cell 131:861-872

71. Yu J, Vodyanik MA, Smuga-Otto K, Antosiewicz-Bourget J, Frane JL, Tian S, Nie J, Jonsdottir GA, Ruotti V, Stewart R, Slukvin II, Thomson JA (2007) Induced pluripotent stem cell lines derived from human somatic cells. Science 318:1917-1920

72. Okano H, Nakamura M, Yoshida K, Okada Y, Tsuji O, Nori S, Ikeda E, Yamanaka S, Miura K (2013) Steps toward safe cell therapy using induced pluripotent stem cells. Cir Res (in press)

73. Ito D, Okano H, Suzuki N (2012) Accelerating progress in iPS cell research for neurological diseases. Ann Neurol 72:167-174

74. Yagi T, Ito D, Okada Y, Akamatsu W, Nihei Y, Yoshizaki T, Yamanaka S, Okano H, Suzuki N (2011) Modeling familial Alzheimer's disease with induced pluripotent stem cells. Hum Mol Genet 20:4530-4539

75. Imaizumi Y, Okada Y, Akamatsu W, Koike M, Kuzumaki N, Hayakawa H, Nihira T, Kobayashi T, Ohyama M, Sato S, Takanashi M, Funayama M, Hirayama A, Soga T, Hishiki T, Suematsu M, Yagi T, Ito D, Kosakai A, Hayashi K, Shouji M, Nakanishi A, Suzuki N, Mizuno Y, Mizushima N, Amagai M, Uchiyama Y, Mochizuki H, Hattori N, Okano H(2012) Mitochondrial dysfunction associated with increased oxidative stress and alpha-synuclein accumulation in PARK2 iPSC-derived neurons and postmortem brain tissue. Mol Brain 5:35 